\title{
Accelerated Cervical Fusion of Silicon Nitride versus PEEK Spacers: A Comparative Clinical Study
}

Hieu T Ball ${ }^{1}$, Bryan J McEntire ${ }^{2}$ and B Sonny Bal ${ }^{2,3^{*}}$

${ }^{1}$ California Comprehensive Spine Institute, 100 Park Place, Suite 140, San Ramon, USA

${ }^{2}$ Amedica Corporation, 1885 W. 2100 S., Salt Lake City, USA

${ }^{3}$ Missouri Orthopaedic Institute, University of Missouri, Columbia, USA

*Corresponding author: B Sonny Bal, Missouri Orthopaedic Institute, University of Missouri, 1100 Virginia Ave., Columbia, USA, Tel: (573) 808-4512; E-mail: balb@health.missouri.edu

Rec Date: May 12, 2017; Acc Date: November 17, 2017; Pub Date: November 21, 2017

Copyright: @ 2017 Bal BS, et al. This is an open-access article distributed under the terms of the Creative Commons Attribution License, which permits unrestricted use, distribution, and reproduction in any medium, provided the original author and source are credited.

\begin{abstract}
Introduction: The ideal material for the manufacture of cervical fusion cages used in anterior cervical discectomy and fusion (ACDF) is undetermined. Spacers made of polyether-ether-ketone (PEEK) are commonly used, although metal and ceramic devices are also commercially available. This observational study compared outcomes of ACDF using two different biomaterial spacers (i.e., PEEK and silicon nitride, $\mathrm{Si}_{3} \mathrm{~N}_{4}$ ).
\end{abstract}

Methods: Twenty consecutive patients who underwent ACDF with $\mathrm{Si}_{3} \mathrm{~N}_{4}$ were retrospectively compared to a group previously implanted with PEEK spacers. Patient demographics, neck pain visual analog scale (VAS) and the neck disability index (NDI) scores were recorded for all enrollees. Cervical radiographs, including flexion-extension views, were examined to determine fusion at $3,6,12,24$, and 36 months post-operatively.

Results: Patient demographics were essentially identical between groups, except for a slightly higher incidence of worker compensation claims in the PEEK group ( $p=0.27)$, and increased prevalence of cervical myelopathy in the $\mathrm{Si}_{3} \mathrm{~N}_{4}$ group $(p=0.12)$. There were no differences in the number of cervical levels treated $(p=0.65)$ or hospital length of stay $(p=0.65)$. No cage failures or infections occurred in either group. At 3,6 , and 12 months, the average flexionextension angular rotation was lower for the $\mathrm{Si}_{3} \mathrm{~N}_{4}$ group as compared to the PEEK cohort. However, these data were not statistically significant. Nevertheless, the incidence of fusion was consistently higher in the $\mathrm{Si}_{3} \mathrm{~N}_{4}$ group at all follow-up visits except 36 months; both groups reached $100 \%$ fusion at the 3-year time-point.

Conclusion: By 36 months, there were no differences in ACDF with PEEK or $\mathrm{Si}_{3} \mathrm{~N}_{4}$ as measured by NDI, VAS, and radiographic fusion of cervical segments. Earlier time points suggested a trend toward enhanced fusion with $\mathrm{Si}_{3} \mathrm{~N}_{4}$. The interim differences may reflect the enhanced bioactive surface of the silicon nitride spacers and/or the radiographic characteristics of each biomaterial.

Keywords: Anterior cervical discectomy and fusion; Polyether-etherketone; Silicon nitride; Intervertebral spinal spacer; Clinical study

\section{Introduction}

Spinal disc spacers are interpositional devices designed to maintain disc height and avoid kyphotic collapse after decompressive discectomy [1]. In the cervical spine, such spacers are used routinely during ACDF. The earliest spacers were made of bone itself (i.e., autograft and allograft) that helped fuse adjacent vertebrae while maintaining disc space [2]. Later, PEEK became widely adopted as a spacer material because of its low cost, radiolucency, and favorable biomechanical properties; PEEK spacers are currently designed with a hollow core that holds bone graft to assist in the fusion process $[3,4]$. However, PEEK is an inert polymer that cannot heal directly to living bone. After in vivo implantation, PEEK elicits an immunologic response manifested by scar and fibrous tissue formation [5]. In contrast, porous metal implants made of titanium alloys (Ti) have a proven track record of predictable bone ingrowth, and are widely used in uncemented femoral stems and acetabular components of total hip replacements [6]. Metals such as porous titanium and porous tantalum have been investigated for use in ACDF spacers and are commonly used $[7,8]$. Recent industry efforts have also targeted the development of PEEK and metal composites to improve the bioactivity and performance of PEEK-only spacers $[9,10]$.

In addition to medical-grade polymers and metals, ceramics are another class of biomaterials. The advantages of oxide ceramics, such as alumina and zirconia, are their superior strength, fracture toughness, and wear properties. These materials have been used in total hip bearings for several decades [11]. In contrast, silicon nitride $\left(\mathrm{Si}_{3} \mathrm{~N}_{4}\right)$ is a non-oxide material that has more recently gained acceptance as a biomaterial [11]. It is one of the toughest synthetic ceramics and has extensive applications in a number of industries such as gas turbines, aerospace, automotive, electronic, and marine environments, where extreme conditions preclude the use of other materials [12]. Silicon nitride is also used to make ACDF spacers, similar in design to PEEK, to restore cervical spine geometry and hold bone graft during the healing process [13]. These ceramic cages have been in clinical use for several years with little published data attesting to their efficacy [14]. $\mathrm{Si}_{3} \mathrm{~N}_{4}$ is biocompatible [15], partially-radioopaque [16], resistant to bacterial adhesion [17-19], and manifests 
Citation: Ball HT, McEntire BJ, Bal BS (2017) Accelerated Cervical Fusion of Silicon Nitride versus PEEK Spacers: A Comparative Clinical

Page 2 of 8

surface bioactivity with rapid healing into host bone within an ovine model [20]. This observational study examined the clinical and radiographic outcomes between $\mathrm{ACDF}$ spacers made of $\mathrm{Si}_{3} \mathrm{~N}_{4}$ and PEEK to see if the surface material properties of the ceramic spacers may lead to earlier fusion.

\section{Materials and Methods}

Following institutional review and approval of the study, 20 consecutive patients who were candidates for ACDF at one or multiple levels underwent implantation of a silicon nitride spacer (Valeo C,
Amedica Corporation, Salt Lake City, UT, USA) (Figure 1a). After providing informed consent, patients were counseled on the surgical procedures, spacer material, and follow-up requirements. Following routine decompression of the intervertebral space, a spacer of the height and width determined by the surgeon was press-fitted into the intervertebral space, with plate and screw fixation of the operated vertebrae. These 20 patients were compared to 21 additional patients who had previously undergone identical surgeries by the same surgeon (H.B.) prior to the use of the $\mathrm{Si}_{3} \mathrm{~N}_{4}$ spacers. This group had cervical stabilization with PEEK spacers (ShurFit Cervical Interbody Cage, Precision Spine, Inc., Parsippany, NJ USA) (Figure 1b).

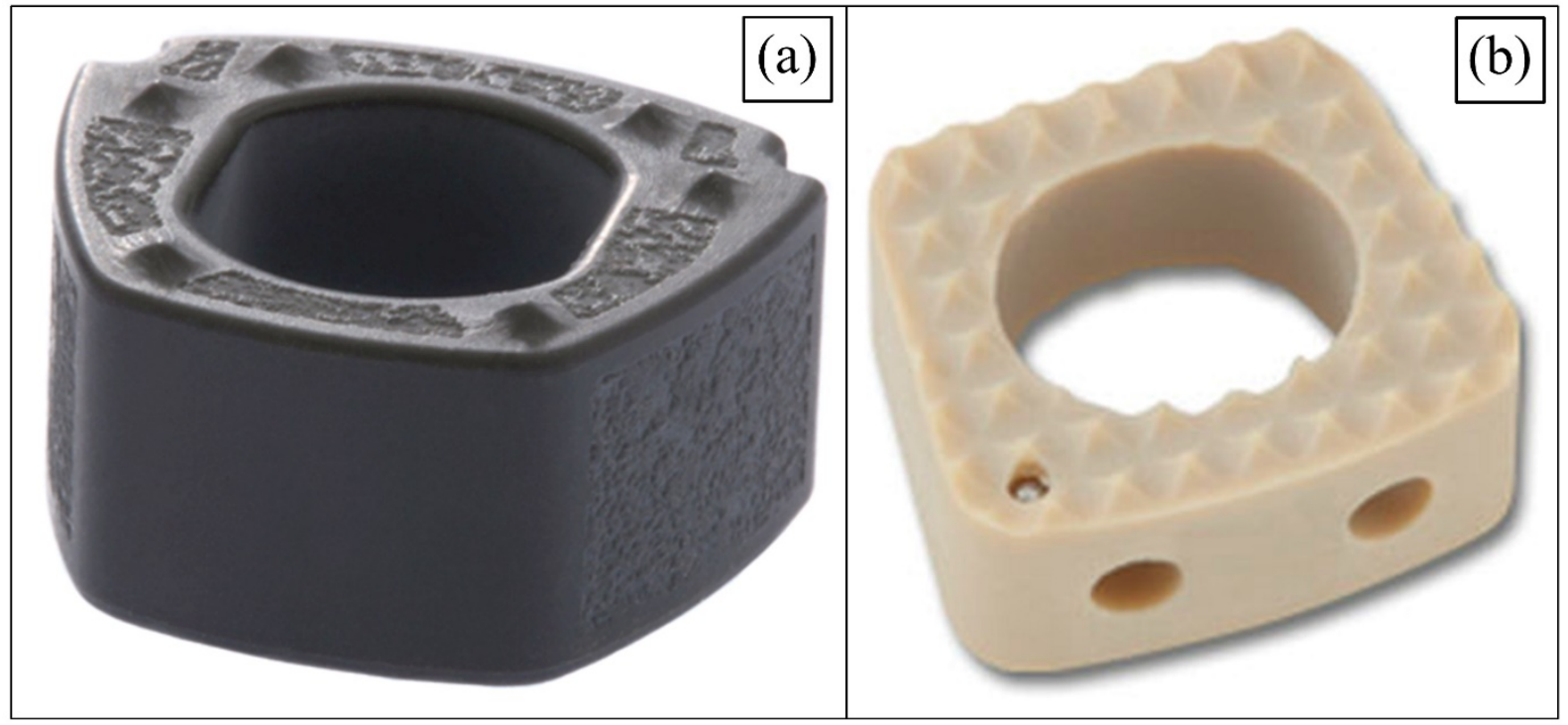

Figure 1: ACDF cages utilized within this study: (a) silicon nitride (Valeo ${ }^{\mathrm{TM}} \mathrm{C}$, Amedica Corporation) and (b) PEEK (ShurFit Cervical Interbody Cage, Precision Spine, Inc.).

\begin{tabular}{|c|c|c|c|}
\hline \multicolumn{2}{|c|}{ Number of Subjects Enrolled } & Group $1-\mathrm{Si}_{3} \mathrm{~N}_{4}$ Spacers $(n=17)$ & Group 2 - PEEK Spacers $(n=21)$ \\
\hline \multirow{2}{*}{ Gender } & Men n/N (\%) & $8 / 17(47 \%)$ & $9 / 21(43 \%)$ \\
\hline & Women $\mathrm{n} / \mathrm{N}(\%)$ & 9/17 (53\%) & $12 / 21(57 \%)$ \\
\hline Age & Mean $\pm \mathrm{SD}(\mathrm{N})$ & $56 \pm 10.4$ & $56 \pm 9.7$ \\
\hline BMI $\left(\mathrm{kg} / \mathrm{m}^{2}\right)$ & Mean \pm SD $(N)$ & $30.72 \pm 7.37(17)$ & $30.22 \pm 4.95(24)$ \\
\hline \multirow{2}{*}{ Current Smoker } & Yes n/N (\%) & $2 / 17(12 \%)$ & $10 / 21(48 \%)$ \\
\hline & No n/N (\%) & 15/17 (88\%) & $11 / 21(52 \%)$ \\
\hline \multirow{2}{*}{ Worker's Compensation Cases } & Yes n/N (\%) & $3 / 20(15 \%)$ & $11 / 25(44 \%)$ \\
\hline & No n/N (\%) & 17/20 (85\%) & $15 / 2556 \%$ \\
\hline
\end{tabular}

Table 1: Summary of patient demographics.

Baseline cervical radiographs, neck pain VAS and NDI scores were obtained of all study enrollees. All cages, regardless of material type, were packed during surgery with a bone graft substitute consisting of hydroxyapatite and tricalcium phosphate $\left(\mathrm{Bi}-\right.$ Ostetic ${ }^{\mathrm{TM}}$, Berkeley Advanced Biomaterials, Inc., Berkeley, CA USA). The graft material was soaked in autogenous bone marrow collected from the bleeding bone of the vertebral bodies. Five patients in the PEEK arm of the study had Medtronic BMP-2 in their cages. This material was used prior to the FDA warning about the risk of complications when BMP-2 is used in the cervical spine. 
Citation: Ball HT, McEntire BJ, Bal BS (2017) Accelerated Cervical Fusion of Silicon Nitride versus PEEK Spacers: A Comparative Clinical Study. J Spine 6: 396. doi:10.4172/2165-7939.1000396

Page 3 of 8

\begin{tabular}{|c|c|c|c|}
\hline \multicolumn{2}{|c|}{ Number of Subjects Enrolled } & Group $1-S_{3} N_{4}$ Spacers $(n=17)$ & Group 2 - PEEK Spacers $(n=21)$ \\
\hline \multirow{4}{*}{ Treated Levels } & 4 Levels $\mathrm{n} / \mathrm{N}(\%)$ & $0 / 17(0 \%)$ & $1 / 21(5 \%)$ \\
\hline & 3 Levels $\mathrm{n} / \mathrm{N}(\%)$ & $4 / 17(23 \%)$ & $7 / 21(33 \%)$ \\
\hline & 2 Levels $\mathrm{n} / \mathrm{N}(\%)$ & $11 / 17(65 \%)$ & $11 / 21(52 \%)$ \\
\hline & 1 Level n/N (\%) & $2 / 17(12 \%)$ & $2 / 21(10 \%)$ \\
\hline \multirow{3}{*}{$\begin{array}{l}\text { Blood Loss } \\
\quad(\mathrm{mL})\end{array}$} & $\leq 50 \mathrm{~mL} \mathrm{n} / \mathrm{N}$ & $10 / 17(59 \%)$ & $19 / 21(90 \%)$ \\
\hline & 51 to $149 \mathrm{~mL}$ & $6 / 17(35 \%)$ & $2 / 21(10 \%)$ \\
\hline & $\geq 150 \mathrm{~mL}$ & $1 / 17(6 \%)$ & 0/21 (05) \\
\hline
\end{tabular}

Table 2: Summary of procedural data.

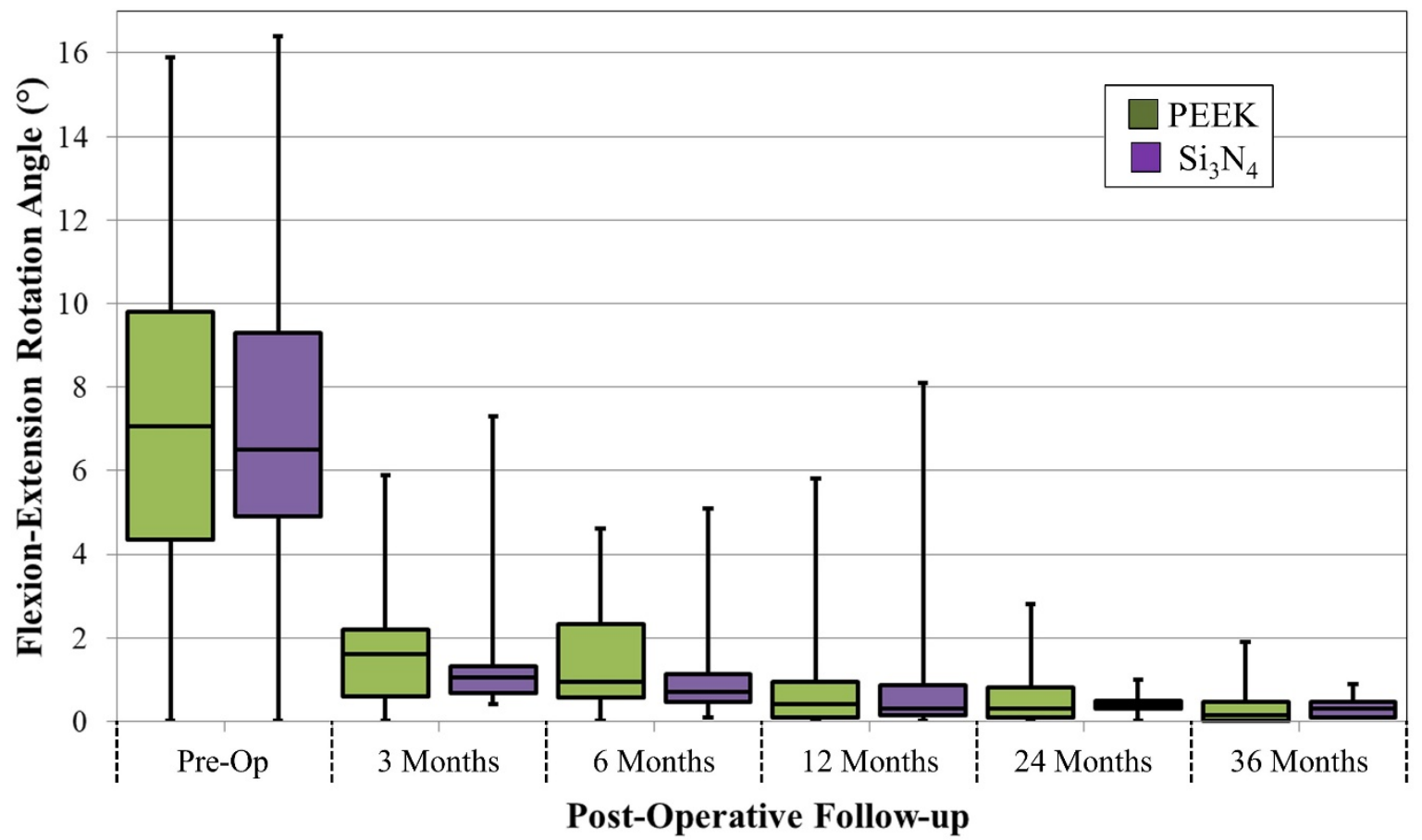

Figure 2: Box and whisker plot for flexion-extension angular rotation at the operative level versus follow-up for $\mathrm{ACDF} P E E K$ and $\mathrm{Si}_{3} \mathrm{~N}_{4}$ spinal spacers.

All patients in each group had supplemental fixation with an anteriorly-placed titanium plate and screws (Slimpicity", Precision Spine, Inc., Parsippany, NJ USA). Patients were immobilized in an Aspen collar for 6 weeks post-operatively, at which time the collar was discontinued, and physical therapy initiated. Routine clinic follow-ups were performed at $3,6,12,24$, and 36 months. At each visit, patients were interviewed and assessed with respect to their overall health and recovery status. They were counseled on the importance of selfmanaged care, lifestyle behavioral changes, (i.e., proper nutrition, exercise, elimination of smoking, etc.), and stress coping skills [21]. Each patient was clinically assessed for neck pain VAS and NDI scores. Cervical radiographs were obtained (including maximum effort flexion-extension projections) and compared to all previous radiographs. Fusion was deemed to have occurred if all of the following criteria were met: (1) improvement in clinical scores over baseline values, (2) No visible continuous radiolucent lines between the implant surface and host bone, $(3) \leq 2$ degrees of flexion-extension rotation or $>50 \%$ reduction in angular rotation compared to preoperative assessments, and $(4) \leq 0.5 \mathrm{~mm}$ sagittal translation of the implant based on the flexion-extension radiographs. Vertebral rotation and translation were independently measured by radiologists trained in a software algorithm, using previously published criteria and methods (Medical Metrics, Inc., Houston, Texas USA) [19]. 
Citation: Ball HT, McEntire BJ, Bal BS (2017) Accelerated Cervical Fusion of Silicon Nitride versus PEEK Spacers: A Comparative Clinical

Because of the retrospective nature of the study, with relatively small patient numbers in each group, categorical data were evaluated with the Fisher's Exact Test, and continuous variables were compared with the Student's t-test. Statistical analyses were performed using StatPlus for Windows software and statistical significance set at $\mathrm{p}<0.05$ (AnalystSoft Inc., Walnut Creek, CA USA).

\section{Results}

Of 20 patients with silicon nitride spacers, one patient declined study participation after initial enrollment, and two others had incomplete operative and/or follow-up data such that they were excluded, thereby leaving 17 patients (37 operated levels; $n=13$ with
1-2 levels, and $n=4$ with 3-4 levels). In the 21 historical control patients with PEEK spacers, 13 patients underwent surgery at 1-2 levels, and 8 underwent ACDF at 3-4 levels, for a total of 44 operated levels. Patient demographic variables (i.e., age, gender, BMI, tobacco use, workers compensation status, and pre-operative myelopathy) did not differ between groups, except for a slightly higher incidence of worker compensation claims in the PEEK group $(p=0.27)$, and increased prevalence of existing cervical myelopathy in the silicon nitride group $(p=0.12)$. There were no significant differences in the number of levels treated $(p=0.65)$ or hospital length of stay $(p=0.65)$ after surgery, and there were no intra-operative complications, cage failures, or infections in either cohort (Tables 1 and 2).
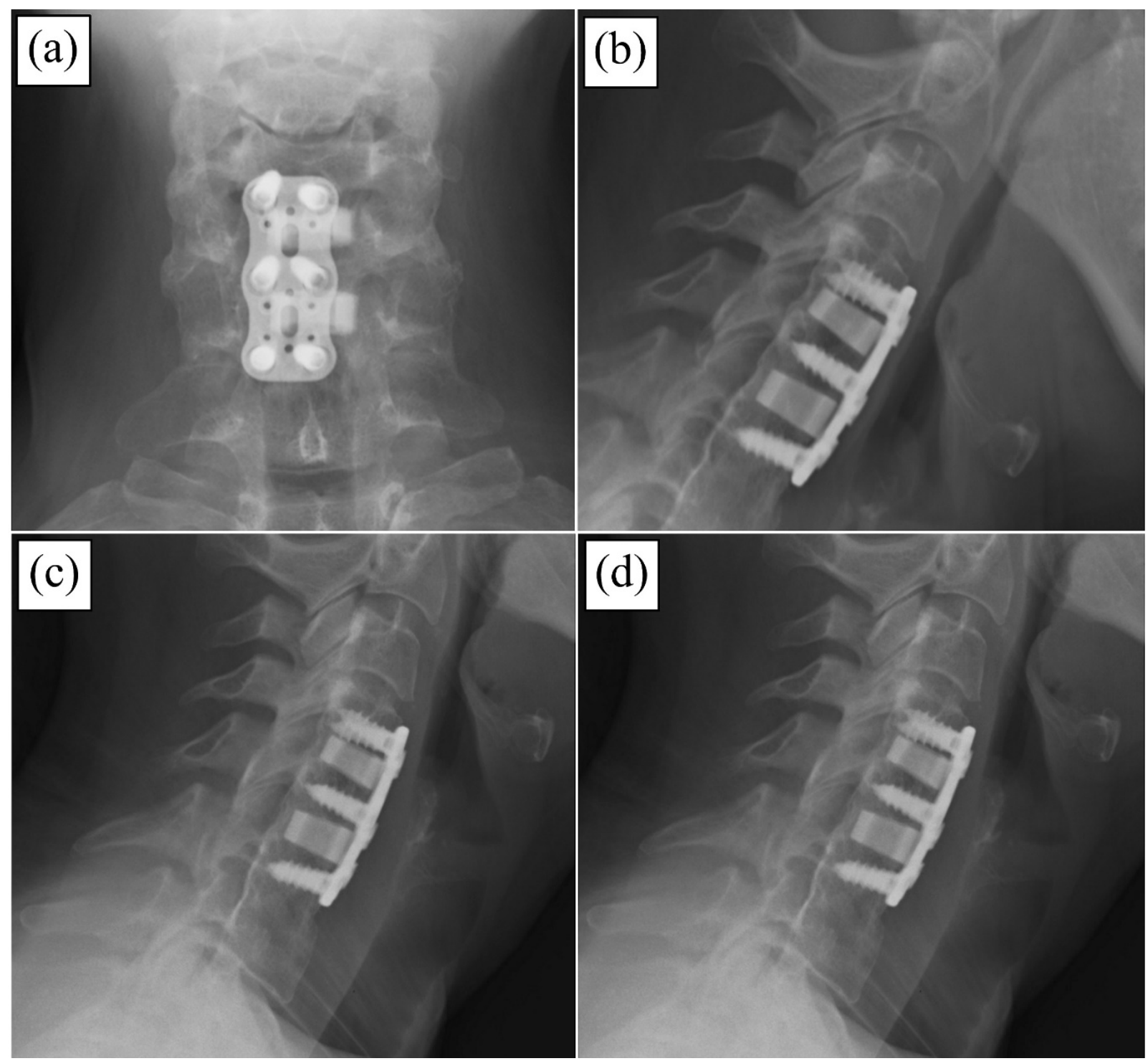

Figure 3: Radiographs for an example $\mathrm{Si}_{3} \mathrm{~N}_{4}$ patient. Patient is 12 months post-operative with $0.2^{\circ}$ of rotation; (a) A-P view; (b) Lateral view; (c) Flexion; and (d) Extension.

Transient dysphagia after surgery was reported by five PEEK patients and by two $\mathrm{Si}_{3} \mathrm{~N}_{4}$ patients. Two of these five PEEK patients also had BMP-2 in their cages which may have contributed to the swelling and dysphagia. The $\mathrm{Si}_{3} \mathrm{~N}_{4}$ group had slightly lower neck pain VAS and NDI scores at the final follow-up, but these differences were not statistically significant. One patient in the PEEK group underwent 
Citation: Ball HT, McEntire BJ, Bal BS (2017) Accelerated Cervical Fusion of Silicon Nitride versus PEEK Spacers: A Comparative Clinical

Page 5 of 8

repeat decompression at the same level 3 months after the index procedure for recurrent symptoms, with cage retention. Another patient with a $\mathrm{Si}_{3} \mathrm{~N}_{4}$ spacer had repeat decompression for recurrent pain at the operated level one year after the index procedure, with cage retention. One patient in the PEEK group had decompression without fusion two levels above the ACDF one year after the index procedure. None of these repeat operations reflected infections or failures attributable to the implants.

Presented in Figure 2 is a box and whisker plot of flexion-extension angular rotation showing changes from the patients' preoperative conditions to their $3,6,12,24$, and 36-month post-operative values. Note that there was a significant reduction in rotational angle at the 3month follow-up $(\mathrm{p}<0.05)$ for both the PEEK and $\mathrm{Si}_{3} \mathrm{~N}_{4}$ groups, but no statistically significant changes in rotation thereafter.

However, the $\mathrm{Si}_{3} \mathrm{~N}_{4}$ implants showed lower average rotational values for at least the first 12 months of the study, perhaps suggesting more effective early arthrodesis. As examples, shown in Figures 3 and 4 are anterior-posterior and lateral flexion-extension $\mathrm{x}$-rays for selected patients implanted with $\mathrm{Si}_{3} \mathrm{~N}_{4}$ and PEEK spacers, respectively. These radiographs indicated effective fusion at 12 months for the $\mathrm{Si}_{3} \mathrm{~N}_{4}$ spacer with $<0.2^{\circ}$ of rotation (Figure 3 ) whereas the PEEK implant at 24 months showed $\approx 2.8^{\circ}$ of rotation (Figure 4 ).

Nevertheless, in spite of these selective examples, there were no statistical differences in rotational angles between the two groups for any of the follow-up visits. As previously discussed, the incidence of fusion was based on broad criteria. It not only included flexionextension angular rotational data, but also utilized VAS and NDI scores, the presence of radiolucent lines at the vertebral endplates, and $\leq 0.5 \mathrm{~mm}$ of sagittal implant translation. Based on these criteria the average incidence of radiographic fusion at the follow-up visits is shown in Figure 5.
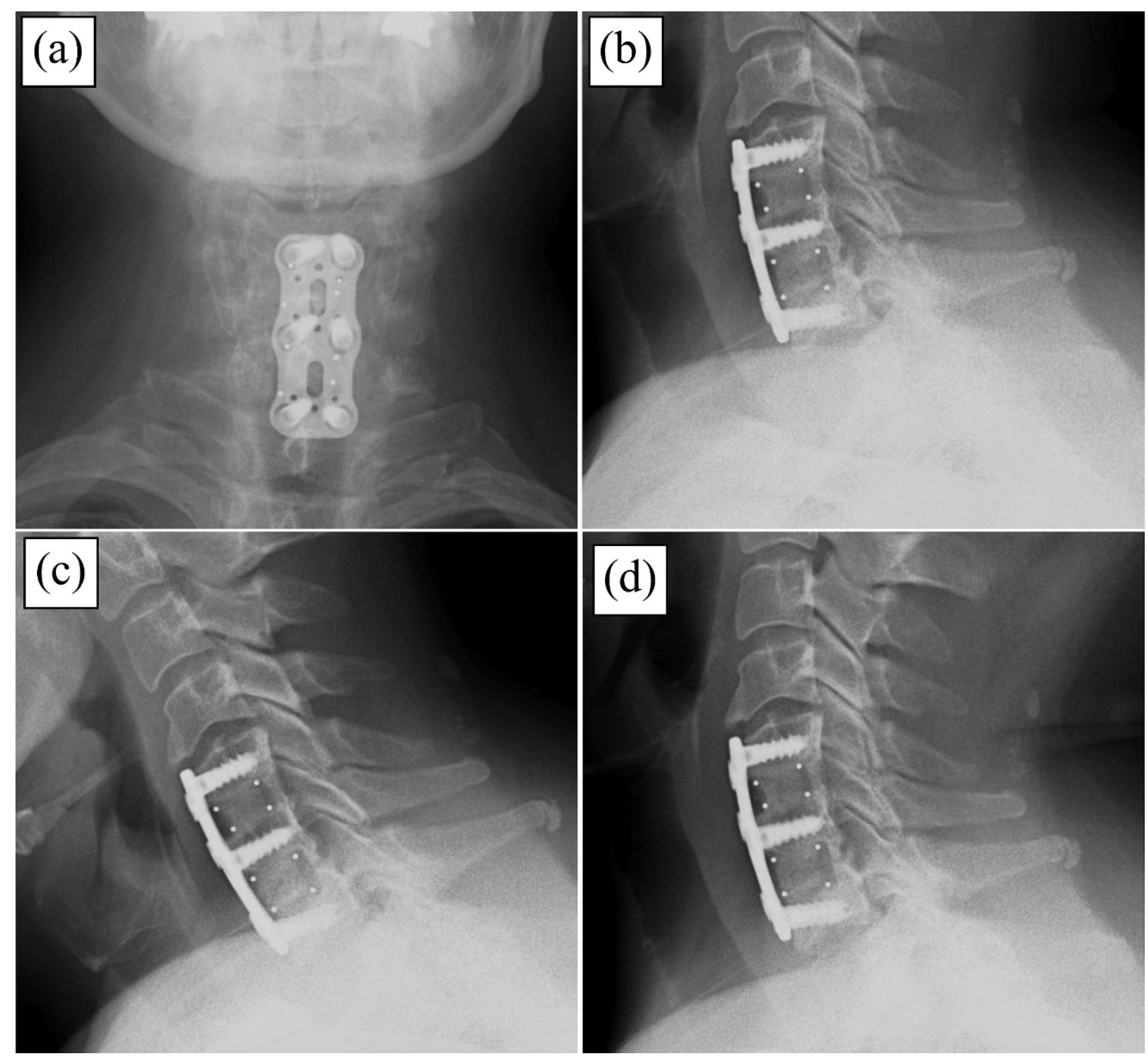

Figure 4: Radiographs for an example PEEK patient. Patient is 24 months post-operative with $2.8^{\circ}$ of rotation; (a) A-P view; (b) Lateral view; (c) Flexion; and (d) Extension. 
These data suggest an early observational advantage for the silicon nitride group as follows: At 3 months $-80.0 \%$ silicon nitride versus 59.5\% PEEK, at 6 months $-83.3 \%$ silicon nitride versus $65.6 \%$ PEEK, at 12 months $-87.0 \%$ silicon nitride versus $85.2 \%$ PEEK, at 24 months - $100 \%$ silicon nitride versus $92.3 \%$ PEEK, and at 36 months - 100\% for silicon nitride and PEEK, respectively. An analysis by Fischer's Exact Test for each of these time-points showed no significant differences, although early data favored the $\mathrm{Si}_{3} \mathrm{~N}_{4}$ group (i.e., p-values of $0.15,0.22,1.00,1.00$, and 1.00 for $3,6,12,24$, and 36 months, respectively. Lastly, at final follow-up, the VAS $(\mathrm{p}=0.39)$ and NDI scores $(\mathrm{p}=0.13)$ did not differ between patients with either the PEEK or $\mathrm{Si}_{3} \mathrm{~N}_{4}$ spacers.

\section{Discussion}

PEEK is a radiolucent material, and therefore, radiolucent lines between the implant and host bone cannot be easily discerned.
Trabecular bone bridging one vertebral body to the next is usually considered a reliable indicator of bone fusion when PEEK spacers are used [22]. In contrast, $\mathrm{Si}_{3} \mathrm{~N}_{4}$ is partially-radiolucent, such that radiolucent lines at the implant-bone interface are readily apparent, while bridging bone can be difficult to see [16]. Because of these differences in imaging characteristics, both subjective and objective measures of bone fusion were employed; the latter relying on softwarederived measures of segment motion using previously-published methodologies $[23,24]$. Based on these criteria, average cervical fusion rates for the silicon nitride spacers were consistently superior at every time point leading to the final follow-up visit.

Radiographic images of the ceramic cages demonstrated bridging bone in front and behind the cages in almost all of the fusions. This may be attributable to a number of factors which allow appositional growth of bone on the ceramic spacer and preclude it on the polymer device.

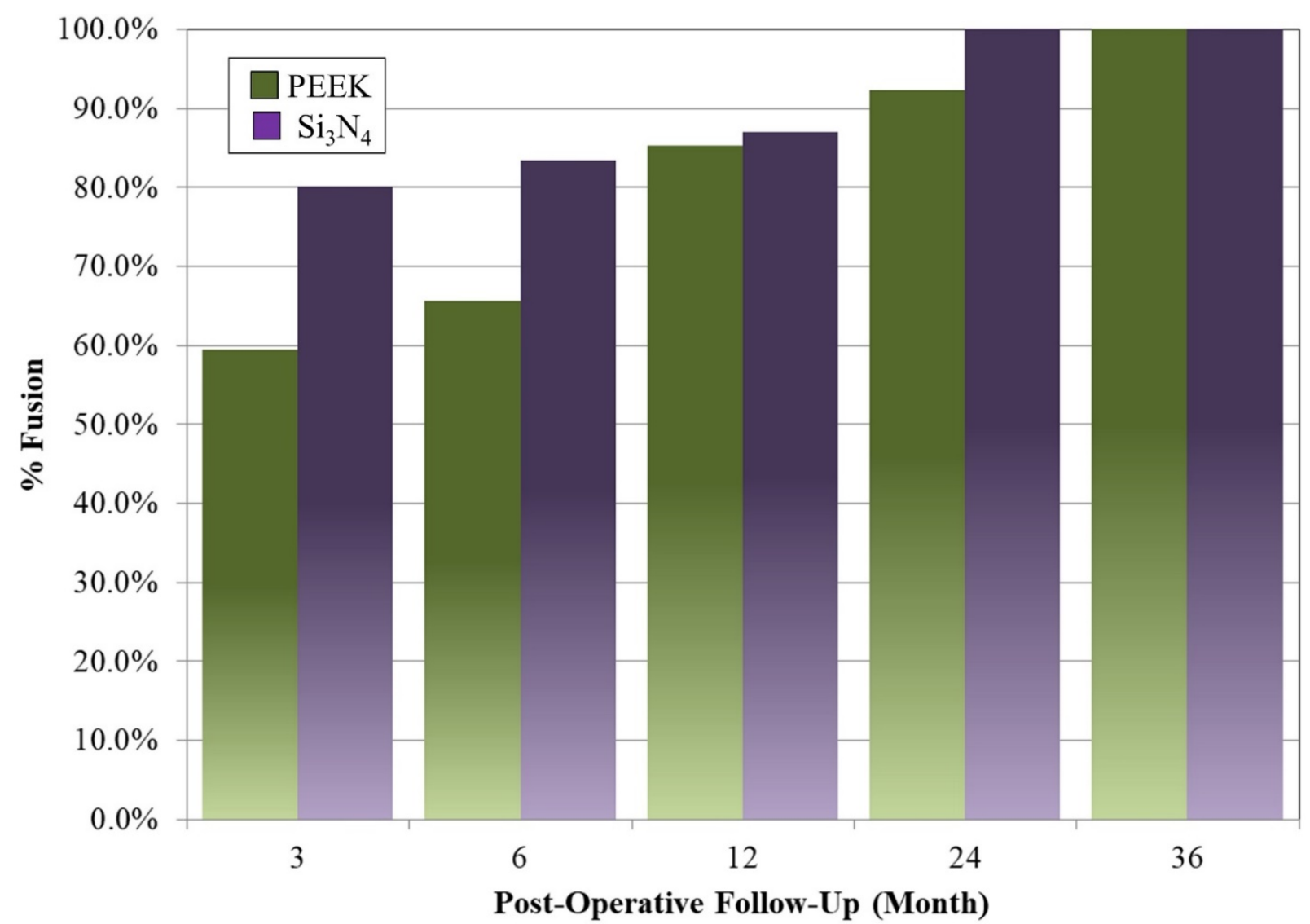

Figure 5: Assessment of \% fusion for ACDF PEEK and $\mathrm{Si}_{3} \mathrm{~N}_{4}$ spinal spacers versus follow-up using objective and subjective criteria including: (i) Improvement in clinical scores over baseline values; (ii) No visible continuous radiolucent lines between the implant surface and host bone; (iii) $\leq 2$ degrees of flexion-extension rotation or $>50 \%$ reduction in angular rotation compared to pre-operative assessments; and (iv) $\leq 0.5$ $\mathrm{mm}$ translation of the implant based on the flexion-extension radiographs.

Published retrieval data on spacers made from $\mathrm{Si}_{3} \mathrm{~N}_{4}$ and PEEK suggest widely different osteointegration behaviors. Host bone grows onto the surface of the ceramic, interdigitating into microscopic pores at the implant surface [25]. In contrast, PEEK spacers cannot achieve osseous stability because PEEK heals with an inflammatory soft tissue response resulting in scarring and fibrosis $[3,5,26]$.
Silicon nitride is well known in industrial applications, but is less familiar than PEEK to spine surgeons. Nevertheless, the material properties of silicon nitride make it ideally suited for bone fusion. These properties include superior material toughness and reliability, biocompatibility, bacterial resistance, stem cell adhesion, and hydrophilicity $[14,17,19,20,27-31]$. This contrasts with PEEK which is 
hydrophobic and lacks any osteogenic surface topography or chemistry $[19,28]$. Silicon nitride favors osteointegration, possessing both osteoconductive and osteoinductive properties; the material can transform pluripotential stem cells into osteoblasts more rapidly than porous $\mathrm{Ti}$ which is a widely-used biomaterial in bone ingrowth applications $[28,29]$. The accelerated fusion attributable to silicon nitride spacers in this study likely resulted from its hydrophilicity, surface topography, and microchemistry. Specifically, the material composition used to make the spacers consisted of $\mathrm{Si}_{3} \mathrm{~N}_{4}$ powders mixed with alumina $\left(\mathrm{Al}_{2} \mathrm{O}_{3}\right)$ and yttria $\left(\mathrm{Y}_{2} \mathrm{O}_{3}\right)$ powders [32]. These latter chemicals are utilized as sintering aids. When densified under high temperature and pressure conditions, this composition leads to partial surface expression of a bioactive glass-like phase on the implant (silicon-yttrium-aluminum-oxynitride, or SiYAlON) [12]. SiYAlON glasses are bioactive, particularly with respect to hydroxyapatite formation [33,34]. Recent data have also shown that SiYAlON glass expression in $\mathrm{Si}_{3} \mathrm{~N}_{4}$ can be modulated by altering the manufacturing conditions [28]. Bioactive glasses encourage bone healing; their in vivo dissolution products attract osteoblasts, and stimulate stem cells to differentiate and produce hydroxyapatite [35,36]. In essence, the $\mathrm{Si}_{3} \mathrm{~N}_{4}$ spacers used in the present study expressed a bioactive, bone void filler material on their surface at the microscopic level. Unlike PEEK, $\mathrm{Si}_{3} \mathrm{~N}_{4}$ 's unique surface chemistry also resists a variety of bacterial species $[17,19,30,37]$. The surface topography of silicon nitride contains anisotropic needlelike grains, with approximate lengths of between 0.5 to $10 \mu \mathrm{m}$ and cross-sectional areas of $<1.0 \mu \mathrm{m}$; these features generate a zwitterionic like surface and are associated with resistance to bacterial adhesion in other materials $[38,39]$. In aqueous, in vivo environments, silicon nitride surfaces release trace amounts of silicic acid $\left(\mathrm{H}_{4} \mathrm{SiO}_{4}\right)$ and ammonia $\left(\mathrm{NH}_{3}\right)$; the latter is a natural disinfectant and is converted to peroxynitrite that contributes to bacterial lysis [30]. The other chemical species, (i.e., silicic acid), is desirable because silicon is essential for bone reformation [40-42].

There are a number of limitations of this study. Its retrospective nature was one of them. It lacked the rigor and governance that are commonly associated with double-blinded randomized controlled trials. The sample size was another obvious limitation. There were an insufficient number of patients both for the control and investigational device groups to provide any clear evidence of superiority or inferiority for either material. Post-hoc statistical analyses for $\%$ fusion suggested that the 3 and 6 -month time-points were powered only to $33.5 \%$ at $\alpha=$ 0.05 . Based on the observed statistical results, the study would have required at least 78 patients in each treatment group at the 3-month time-point and 94 patients in each group at six-month follow-up. Even higher enrollments would have been required for longer periods. Multivariate regression analyses were also conducted for data from each treatment group to see if patient demographic factors (i.e., sex, ethnicity, age, BMI, or smoker) played any role in the observed results. Unfortunately, these analyses were also inconclusive due to low $\mathrm{n}$ values in both groups. One final limitation was the lack of computed tomography (CT) adjudication of bone fusion. No CT data were acquired for either treatment group. CT evidence may have indicated that actual bone penetration occurred into the rough as-fired surfaces of the $\mathrm{Si}_{3} \mathrm{~N}_{4}$ spacers; whereas the likely result for PEEK was fibrous encapsulation.

\section{Conclusion}

These clinical data suggest that the material properties of $\mathrm{Si}_{3} \mathrm{~N}_{4}$ may contribute to accelerated fusion rates over PEEK, at least up to 24 months after surgery. The results showed smaller average flexionextension angular rotational values for the $\mathrm{Si}_{3} \mathrm{~N}_{4}$ spacers at 3,6 and 12 months post-operatively; and higher average \% fusion for all timepoints except the final 3-year follow-up. Study limitations include the retrospective nature of this investigation, small patient numbers that were not amenable to statistical power analysis, differences in radiographic appearance of the two materials used, and lack of CT data to verify the extent of bone ingrowth into the $\mathrm{Si}_{3} \mathrm{~N}_{4}$ spacers or lack thereof in the PEEK cages. Despite these limitations, the present data suggest that further clinical investigations with larger patient numbers are warranted to validate the advantages of silicon nitride in spine fusion.

\section{References}

1. Chong E, Pelletier MH, Mobbs RJ, Walsh WR (2015) The design evolution of interbody cages in anterior cervical discectomy and fusion: a systematic review. BMC Musculoskeletel Disord 16: 1-11.

2. Faldini C, Leonetti D, Nanni M, Martino AD, Denaro L, et al. (2010) Cervical disc herniation and cervical spondylosis surgically treated by cloward procedure: a 10-year-minimum follow-up study. J Orthop Traumatol 11: 99-103.

3. Lemcke J, Al-Zain F, Meier U, Suess O (2011) Polyetheretherketone (PEEK) Spacers for anterior cervical fusion: a retrospective comparative effectiveness clinical trial. Open Orthop J 5: 348-353.

4. Tumialán LM, Pan J, Rodts GE, Mummaneni PV (2008) The safety and efficacy of anterior cervical discectomy and fusion with polyetheretherketone spacer and recombinant human bone morphogenetic protein-2: A review of 200 patients. J Neurosurg Spine 8: 529-535.

5. Olivares-Navarrete R, Hyzy SL, Slosar PJ, Schneider JM, Schwartz Z, et al. (2015) Implant materials generate different peri-implant inflammatory factors: poly-ether-ether-ketone promotes fibrosis and microtextured titanium promotes osteogenic factors. Spine (Phila. Pa. 1976) 40: 399-404.

6. Olivares-Navarrete R, Hyzy SL, Gittens RA, Schneider JM, Haithcock DA, et al. (2013) Rough titanium alloys regulate osteoblast production of angiogenic factors. Spine J 13: 1563-1570.

7. Hanc M, Fokter SK, Vogrin M, Molicnik A, Recnik G (2016) Porous tantalum in spinal surgery: An overview. Eur J Orthop Surg Traumatol 26: 1-7.

8. Wu SH, Li Y, Zhang YQ, Li XK, Yuan CF, et al. (2013) Porous titanium-6 aluminum-4 vanadium cage has better osseointegration and less micromotion than a poly-ether-ether-ketone cage in sheep vertebral fusion. Artif Organs 37: E191-E201.

9. Kurtz SM, Devine JN (2007) PEEK biomaterials in trauma, orthopedic, and spinal implants. Biomaterials 28: 4845-4869.

10. Ma R, Tang T (2014) Current strategies to improve the bioactivity of PEEK. Int J Mol Sci 15: 5426-5445.

11. McEntire BJ, Bal BS, Rahaman MN, Chevalier J, Pezzotti G (2015) Ceramics and ceramic coatings in orthopaedics. J Eur Ceram Soc 35: 4327-4369.

12. Riley FL (2000) Silicon nitride and related materials. J Am Ceram Soc 83: 245-265.

13. Mazzocchi M, Bellosi A (2008) On the possibility of silicon nitride as a ceramic for structural orthopaedic implants. part i: processing, microstructure, mechanical properties, cytotoxicity. J Mater Sci Mater Med 19: 2881-2887.

14. Bal BS, Rahaman MN (2012) Orthopedic applications of silicon nitride ceramics. Acta Biomater 8: 2889-2898.

15. Neumann A, Reske T, Held M, Jahnke K, Ragoss C, et al. (2004) Comparative investigation of the biocompatibility of various silicon nitride ceramic qualities in vitro. J Mater Sci Mater Med 15: 1135-1140.

16. Anderson M, Bernero J, Brodke D (2008) Medical imaging characteristics of silicon nitride ceramic a new material for spinal arthroplasty implants. 
in 8th annual spine arthroplasty society global symposium on motion preservation technology. Miami, FL, pp: 547.

17. Gorth DJ, Puckett S, Ercan B, Webster TJ, Rahaman M, et al. (2012) Decreased bacteria activity on Si3N4 surfaces compared with peek or titanium. Int J Nanomedicine 7: 4829-4840.

18. Wang M, Bhardwaj G, Webster $T$ (2017) Antibacterial properties of PEKK for orthopedic applications. Int J Nanomedicine 12: 6471-6476.

19. Bock RM, Jones EN, Ray DA, Bal BS, Pezzotti G, et al. (2017) Bacteriostatic behavior of surface-modulated silicon nitride in comparison to polyethereetherketone and titanium. J Biomed Mater Res 105: 1521-1534.

20. Anderson MC, Olsen R (2010) Bone ingrowth into porous silicon nitride. J Biomed Mater Res 92: 1598-1605.

21. Ciccone MM, Aquilino A, Cortese F, Scicchitano P, Sassara M, et al. (2010) Feasibility and effectiveness of a disease and care management model in the primary health care system for patients with heart failure and diabetes (project leonardo). Vasc Health Risk Manag 6: 297-305.

22. Liao JC, Niu CC, Chen WJ, Chen LH (2008) Polyetheretherketone (PEEK) cage filled with cancellous allograft in anterior cervical discectomy and fusion. Int Orthop 32: 643-648.

23. Taylor M, Hipp JA, Gertzbein SD, Gopinath S, Reitman CA (2007) Observer agreement in assessing flexion-extension $\mathrm{x}$-rays of the ceravical spine, with and without the use of quantitative measurements of intervertebral motion. Spine J 7: 654-658.

24. Ghiselli G, Jatana S, Wong DA, Wharton ND (2007) Prospective analysis of imaging prediction of pseudarthrosis after anterior cervical discectomy and fusion: computed tomography vs. flexion- extension motion analysis with intraoperative confirmation. Spine J Meet Abstr 106-107.

25. Pezzotti G, Oba N, Zhu W, Marin E, Rondinella A, et al. (2017) Human osteoblasts grow transitional si/n apatite in quickly osteointegrated Si3N4 cervical insert. Acta Biomater 64: 411-420.

26. Phan K, Hogan JA, Assem Y, Mobbs RJ (2016) PEEK-Halo effect in interbody fusion. J Cinical Neurosci 24: 138-140.

27. Taylor RM, Bernero JP, Patel AA, Brodke DS, Khandkar AC (2010) Silicon nitride - A new material for spinal implants. J Bone Jt Surg 92: 133.

28. Bock RM, McEntire BJ, Bal BS, Rahaman MN, Boffelli M, et al. (2015) Surface modulation of silicon nitride ceramics for orthopaedic applications. Acta Biomater 26: 318-330.

29. Pezzotti G, McEntire BJ, Bock RM, Zhu W, Boschetto F, et al. (2016) In situ spectroscopic screening of osteosarcoma living cells on stoichiometry-modulated silicon nitride bioceramic surfaces. ACS Biomater Sci Eng 2: 1121-1134.
30. Pezzotti G, Bock RM, McEntire BJ, Jones E, Boffelli M, et al. (2016) Silicon nitride bioceramics induce chemically driven lysis in porphyromonas gingivalis. Langmuir 32: 3024-3035.

31. Pezzotti G, Marin E, Adachi T, Rondinella A, Boschetto F, et al. (2017) Bioactive silicon nitride: A new therapeutic material for osteoarthropathy. Sci Rep 7: 44848.

32. McEntire BJ, Lakshminarayanan R, Thirugnanasambandam P, SeitzSampson J, Bock R, et al. (2016) Processing and characterization of silicon nitride bioceramics. Bioceram Dev Appl 6: 093.

33. Bachar A, Mercier C, Tricoteaux A, Hampshire S, Leriche A, et al. (2013) Effect of nitrogen and fluorine on mechanical properties and bioactivity in two series of bioactive glasses. J Mech Behav Biomed Mater 23: 133-148.

34. Bachar A, Mercier C, Tricoteaux A, Leriche A, Follet C, et al. (2012) Effects of addition of nitrogen on bioglass properties and structure. J Non Cryst Solids 358: 693-701.

35. Kent Leach J, Kaigler D, Wang Z, Krebsbach PH, Mooney DJ (2006) Coating of VEGF-releasing scaffolds with bioactive glass for angiogenesis and bone regeneration. Biomaterials 27: 3249-3255.

36. Jones JR, Lin S, Yue S, Lee PD, Hanna JV, et al. (2010) Bioactive glass scaffolds for bone regeneration and their hierarchical characterisation. Proc Inst Mech Eng H 224: 1373-1387.

37. Webster TJ, Patel AA, Rahaman MN, Bal BS (2012) Anti-Infective and osteointegration properties of silicon nitride, poly (ether ether ketone), and titanium implants. Acta Biomater 8: 4447-4454.

38. Tsukruk VV, Bliznyuk VN (1998) Adhesive and friction forces between chemically modified silicon and silicon nitride surfaces. Langmuir 14: 446-455.

39. Ivanova EP, Hasan J, Webb HK, Truong VK, Watson GS, et al. (2012) Natural bactericidal surfaces: mechanical rupture of pseudomonas aeruginosa cells by cicada wings. Small 8: 2489-2494.

40. Reffitt DM, Ogston N, Jugdaohsingh R, Cheung HFJ, Evans BA, et al (2003) Orthosilicic acid stimulates collagen type 1 synthesis and osteoblastic differentiation in human osteoblast-like cells in vitro. Bone 32: $127-135$

41. Jugdaohsingh R (2007) Silicon and bone health. J Nutr Heal Aging 11: 99-110.

42. Price CT, Koval KJ, Langford JR (2013) Silicon: A review of its potential role in the prevention and treatment of post-menopausal osteoporosis. Int J Endocrinol. 